\title{
Why do women doctors in the UK take hormone replacement therapy?
}

\author{
A J Isaacs, A R Britton, Klim McPherson
}

\begin{abstract}
Study objectives-To ascertain the determinants and experiences of hormone replacement therapy (HRT) use by menopausal women doctors.

Design-Postal questionnaire.

Setting-UK.

Patients-A randomised stratified sample of women doctors who obtained full registration between 1952 and 1976, taken from the current Principal List of the UK Medical Register.
\end{abstract}

Main outcome measures-Current and previous use of HRT; reasons for and against HRT use; menopausal status; hormonal contraceptive use; lifestyle patterns; family and personal history of disease.

Main results-While $73.2 \%$ of 471 users had started HRT for symptom relief, $60.9 \%$ cited prevention of osteoporosis and $32.7 \%$ prevention of cardiovascular disease. Altogether $18.7 \%$ had started for preventive purposes alone. Significant predisposing factors to starting HRT were the presence and severity of menopausal symptoms, surgical menopause, past use of hormonal contraception, and a family history of osteoporosis. HRT users were also more likely to use skimmed rather than full fat milk, to try to increase their intake of fruit, vegetables, and fibre, and to undertake vigorous physical activity at least once a week. They were less likely to have had breast cancer. Long duration users were more likely than short duration users to be past users of hormonal contraception and to be using HRT for prevention of osteoporosis as well as symptom relief; they were less likely to have experienced side effects.

Conclusions-The high usage of HRT by women doctors reflects the fact that many started HRT on their own initiative and with long term prevention in mind. The results may become generalisable to the wider population as information on the potential benefits of HRT is disseminated and understood. However, HRT users may differ slightly from non-users in healthrelated behaviour and a substantial minority may never take up HRT, at least until the benefit-risk ratio is more clearly established.

(f Epidemiol Community Health 1997;51:373-377)

Women doctors have relatively high utilisation rates of hormone replacement therapy (HRT) and appear to continue use for several years. ${ }^{1}$
As part of a detailed survey, information was obtained on the determinants of HRT use among women doctors as well as their preferences and experiences. Since they are not only a well informed group, but in a strong position to influence the behaviour of other women, knowledge about these factors may be helpful in predicting the uptake of HRT in the wider population.

It is generally considered that the benefits of long term HRT in reducing the risk of osteoporotic fracture ${ }^{2}$ and coronary heart disease $^{3}$ in postmenopausal women outweigh potential adverse effects, such as an increased breast cancer risk, ${ }^{4}$ and contribute to an increase in life expectancy. ${ }^{5}$ Since it has been suggested, that women who take HRT adopt healthier lifestyles (with the possible exception of cigarette smoking) than those who do not, thus exaggerating the benefit seen in observational studies, ${ }^{67}$ evidence for such associations was sought in this group of women doctors surveyed.

\section{Methods}

The sampling and survey method has previously been described in detail. ${ }^{1}$ A stratified randomised sample of 1514 women doctors who obtained full registration with the General Medical Council between 1952 and 1976 inclusive and whose names appeared on the Principal List of the Medical Register received a postal questionnaire in June 1993. Following reminders, 1211 responses were received and coded and the data entered into a computerised data base. Statistical analyses were carried out using Epi-Info, ${ }^{8}$ with multiple logistic regression to standardise for age using SPSS. ${ }^{9}$

Respondents were characterised by year of full registration, place of qualification, and home address from the Medical Register. The questionnaire covered the type of work, date of birth, weight and height, date of menarche and menopause, menopausal status, type of menopause, symptoms, HRT use, reasons for starting, stopping or never taking HRT, duration and type of treatment, side effects, reproductive history including use of hormonal contraceptives, smoking history, exercise and dietary patterns (table 1), family and personal history and attitudes to HRT use among the premenopausal group. Results from the latter group will be reported separately.

\section{Results}

MENOPAUSAL STATUS

Periods had ceased completely in 771 women, while 45 were perimenopausal, 93 had started 
Table 1 Lifestyle questions

* Do you undertake vigorous activity sufficient to become

breathless or perspire at least once a week?

* Which type of bread do you eat mainly?

White/Brown/Wholemeal

What spread do you use mainly?

Butter/Soft margarine/Low fat spread

* What milk do you drink mainly?

Full fat/Semi-skimmed/Skimmed

Do you eat fried food on average-twice a week or less?

more than twice a week?

Do you avoid or restrict your intake of certain types of food? - If yes, please specify

* Do you try to increase your intake of certain types of food? - If yes, please specify

HRT before the menopause, and 302 were still menstruating regularly. Altogether 186 women had had a hysterectomy.

PREVALENCE OF HRT USE

Overall, 480 of the 1211 respondents $(39.6 \%)$

had ever used HRT, of whom $344(28.4 \%$ of the whole group) were still using it. If women still menstruating regularly are excluded, 472 out of 909 (51.9\%) had ever used HRT.

CHARACTERISTICS OF WOMEN BY AGE

The distribution of some key variables by broad age band (excluding the premenopausal group) is shown in table 2. Ever use of hormonal contraception was particularly strongly correlated with age.

REASONS FOR HRT USE

Of the 471 women responding to this question, $73.2 \%$ cited symptom relief, $60.9 \%$ prevention of osteoporosis, and $32.7 \%$ prevention of cardiovascular disease. Cardiovascular prevention was cited more commonly by the younger women (table 2). Fifty eight women had no menopausal symptoms, among whom $82.8 \%$ took HRT for prevention of osteoporosis, $41.4 \%$ for prevention of cardiovascular disease, and $37.9 \%$ for other reasons. In all, 126 of the 471 women $(26.8 \%)$ had started HRT for reasons other than symptom relief, of whom 88 gave only prevention of osteoporosis and/or cardiovascular disease as their reason (55 osteoporosis alone, 4 cardiovascular disease alone, and 29 both). In $76.2 \%$ it was the woman's own idea to start HRT, $11.4 \%$ began on the advice of a gynaecologist and $7.8 \%$ on the GP's advice. Younger women were particularly likely to start HRT on their own initiative (table 2).

\section{TYPE OF HRT USE}

Altogether $86.8 \%$ of the 471 women had taken oral HRT, $33.3 \%$ patches, and $5.7 \%$ implants. Altogether $32.7 \%$ had used oestrogen only preparations and $71.5 \%$ combined formulations A large number of preparations had been used including ad hoc combinations of oral therapy and patches with several different progestogens. Conjugated equine oestrogens had been used longest by $47.1 \%$ of HRT ever-users and transdermal preparations by $14.5 \%$. Of the 105 women who had used both tablets and patches, 41 preferred tablets and 33 patches. The main
KEY POINTS

- The high personal use of HRT by UK women doctors reflects a belief in prevention, particularly of osteoporosis, and suggests that usage will probably increase in the general female population.

- Increasing use of oral contraceptives by successive cohorts of women may predispose to a future increased uptake of HRT.

- HRT users tend to adopt healthier behaviour patterns that non-users, which may reduce the amount of benefit apparently attributable to long term HRT in epidemiological studies.

- Until concerns over withdrawal bleeding and potential cancer risk are satisfactorily allayed many women will not use HRT.

- Randomised controlled trials are required to allow unbiased evaluation of the benefit and risk of HRT.

reasons cited for preferring tablets were that the patches caused skin irritation (17 women) or came off (9). Patches were preferred because they produced no, or fewer, side effects (14 women) or were thought better for liver function (5). Tablets were considered easier to use or remember by 8 women and patches by 9 . Of the 16 women who had tried implants and at least one other route of administration, 7 preferred implants, 5 tablets, and 4 patches.

SIDE EFFECTS

Side effects had been experienced by $48.1 \%$ of the sample. The most common, regardless of type of preparation, were weight gain, breast tenderness/swelling, bloating/oedema, headache/migraine, problems associated with bleeding, and depression/irritability. In all, 329 side effects were mentioned by 220 women, but these resulted in discontinuation of HRT in only 81 cases.

\section{REASONS FOR STOPPING HRT}

Nearly a quarter of past users (32) had stopped because of problems associated with bleeding or simply because they did not wish to continue bleeding. Other reasons included weight gain (17), fluid retention and bloating (11), headache, migraine, and neurological problems (13), depression and irritability (9), breast disease or mastalgia (11) and breast cancer (7). Nineteen women stopped because their symptoms abated, 14 because they felt they had been taking treatment long enough, and 10 because it was not helping.

\section{REASONS FOR NOT USING HRT}

A total of 426 of the 437 menopausal women who had never used HRT responded to this question. In $30.5 \%$ it was because they had not had menopausal symptoms and in $48.8 \%$ because their symptoms were tolerable. Altogether $22.3 \%$ were concerned about side effects (mainly breast cancer, a fear of cancer in general, and problems associated with bleeding) 
Table 2 Characteristics of women by age (excluding the premenopausal women) $\left(n=895^{*}\right)$

\begin{tabular}{|c|c|c|c|}
\hline \multirow[t]{2}{*}{ Variable } & Age & & \\
\hline & $\begin{array}{l}<55 y \\
(n=263)\end{array}$ & $\begin{array}{l}55-59 y \\
(n=246)\end{array}$ & $\begin{array}{l}60+y \\
(n=386)\end{array}$ \\
\hline Place of qualification & & & \\
\hline UK & $204(78.8) \dagger$ & $210(86.4)$ & $323(83.9)$ \\
\hline Indian subcontinent & $40(15.4)$ & $22(9.1)$ & $21(5.5)$ \\
\hline Elsewhere & $15(5.8)$ & $11(4.5)$ & $41(10.6)$ \\
\hline Main work & & & \\
\hline Hospital & $90(34.2)$ & $68(27.6)$ & $66(17.1)$ \\
\hline General practice & $85(32.3)$ & $71(28.9)$ & $70(18.1)$ \\
\hline Community health & $56(21.3)$ & $48(19.5)$ & $47(12.2)$ \\
\hline Public health med & $7(2.7)$ & $10(4.1)$ & $3(0.8)$ \\
\hline Other & $13(4.9)$ & $22(8.9)$ & $32(8.3)$ \\
\hline Retired & $12(4.6)$ & $27(11.0)$ & $169(43.5)$ \\
\hline Body mass index & & & \\
\hline $15-19$ & $25(9.8)$ & $15(6.3)$ & $29 \quad(7.8)$ \\
\hline $20-24$ & $157(61.8)$ & $138(57.7)$ & $198(52.9)$ \\
\hline $25-29$ & $56(22.0)$ & $70(29.3)$ & $124(33.2)$ \\
\hline $30+$ & $16(6.3)$ & $16(6.7)$ & $23(6.1)$ \\
\hline Cause of menopause & & & \\
\hline Natural & $201(76.4) \ddagger$ & $178(76.1)$ & $300(78.9)$ \\
\hline Surgical & $56(21.3)$ & $49(20.9)$ & $78(20.5)$ \\
\hline Other & $6(2.3)$ & $7(3.0)$ & $2(0.5)$ \\
\hline Menopausal symptoms & & & \\
\hline Yes & $212(80.6)$ & $209(85.0)$ & $262(67.9)$ \\
\hline No & $51(19.4)$ & $37(15.0)$ & $124(32.1)$ \\
\hline Vasomotor symptoms & & & \\
\hline None & $66(25.1)$ & $49(19.9)$ & $138(35.8)$ \\
\hline Mild & $106(40.3)$ & $81(32.9)$ & $139(36.0)$ \\
\hline Moderate & $62(23.6)$ & $82(33.3)$ & $78(20.2)$ \\
\hline Severe & $29(11.0)$ & $34(13.8)$ & $31(8.0)$ \\
\hline Genitourinary sympton & & & \\
\hline None & $171(65.0)$ & $158(64.2)$ & $287(74.4)$ \\
\hline Mild & $55(20.9)$ & $61(24.8)$ & $61(15.8)$ \\
\hline Moderate & $33(12.5)$ & $23(9.3)$ & $31(8.0)$ \\
\hline Severe & $4(1.5)$ & $4(1.6)$ & 7 (1.8) \\
\hline Ever use of non-hormo & for the menop & & \\
\hline Yes & $33(13.9)$ & $23(10.1)$ & $43(12.0)$ \\
\hline No & $205(86.1)$ & $205(89.9)$ & $316(88.0)$ \\
\hline Previous pregnancy & & & \\
\hline Yes & $224(86.5)$ & $219(89.0)$ & $290(75.5)$ \\
\hline No & $35(13.5)$ & $27(11.0)$ & $94(24.5)$ \\
\hline Parity & & & \\
\hline None & $46(17.8)$ & $33(13.4)$ & $109(28.4)$ \\
\hline 1 or 2 & $136(52.5)$ & $94(38.2)$ & $113(29.4)$ \\
\hline $3+$ & $77(29.7)$ & $119(48.4)$ & $162(42.2)$ \\
\hline Ever use of hormonal & & & \\
\hline Yes & $189(72.7)$ & $131(53.5)$ & $139(36.1)$ \\
\hline No & $71(27.3)$ & 114 (45.5) & $246(63.9)$ \\
\hline Smoking & & & \\
\hline Never & $189(72.4)$ & $161(65.7)$ & $207(53.7)$ \\
\hline Past & $52(19.9)$ & $72(29.4)$ & $150(39.0)$ \\
\hline Current & $20(7.7)$ & $12(4.9)$ & $28(7.3)$ \\
\hline Exercise & & & \\
\hline Yes & $123(47.5)$ & $119(48.8)$ & $181(47.5)$ \\
\hline No & $136(52.5)$ & $125(51.2)$ & $200(52.4)$ \\
\hline Milk & & & \\
\hline Full fat & $39(15.5)$ & $45(19.0)$ & $110(29.3)$ \\
\hline Semi-skimmed & $150(59.8)$ & $129(54.4)$ & $179(47.7)$ \\
\hline Skimmed & $62(24.7)$ & $63(26.6)$ & $86(22.9)$ \\
\hline Bread & & & \\
\hline White & $40(15.5)$ & $34(14.3)$ & $58(15.3)$ \\
\hline Brown & $60(23.3)$ & $57(23.9)$ & $81(21.3)$ \\
\hline Wholemeal & $158(61.2)$ & $147(61.8)$ & $241(63.4)$ \\
\hline Spread & & & \\
\hline Butter & $93(37.5)$ & $88(40.0)$ & $152(43.1)$ \\
\hline Margarine & $48(19.4)$ & $48(21.8)$ & $69(19.5)$ \\
\hline Low fat spread & $107(43.1)$ & $84(38.2)$ & $132(37.4)$ \\
\hline Increase certain foods & & & \\
\hline Yes & $167(65.0)$ & $141(57.6)$ & $218(56.9)$ \\
\hline No & $90(35.0)$ & $104(42.4)$ & $165(43.1)$ \\
\hline Avoid/restrict certain fo & & & \\
\hline Yes & $202(78.0)$ & $198(80.8)$ & $289(75.3)$ \\
\hline No & $57(22.0)$ & $47(19.2)$ & $95(24.7)$ \\
\hline Fried food & & & \\
\hline$<$ twice a week & $247(95.0)$ & $240(97.6)$ & $364(94.3)$ \\
\hline >twice a week & $13(5.0)$ & $6(2.4)$ & $22(5.7)$ \\
\hline Ever use of HRT & & & \\
\hline Yes & $165(62.7)$ & $151(61.4)$ & $147(38.1)$ \\
\hline No & $98(37.3)$ & $95(38.6)$ & $239(61.9)$ \\
\hline Women who have used & $(n-165)$ & $(n-151)$ & $(n-147)$ \\
\hline Whose idea & $(n=165)$ & $(n=131)$ & $(n=14 t)$ \\
\hline Self & $118(81.9)$ & $105(78.4)$ & $95(67.9)$ \\
\hline Other & $26(18.1)$ & $29(21.6)$ & $45(32.1)$ \\
\hline Reasons for use: & & & \\
\hline Symptom relief & & & \\
\hline Yes & $118(77.6)$ & $107(76.4)$ & $95(65.1)$ \\
\hline No & $34(22.4)$ & $33(23.6)$ & $51(34.9)$ \\
\hline To prevent osteoporo & & & \\
\hline Yes & $96(63.2)$ & $91(65.0)$ & $80(54.8)$ \\
\hline No & $56(36.8)$ & $49(35.0)$ & $66(45.2)$ \\
\hline To prevent cardiovas & & & \\
\hline $\begin{array}{l}\text { Yes } \\
\text { No }\end{array}$ & $58(38.2)$ & $51(36.4)$ & $33(22.6)$ \\
\hline No & $94(61.8)$ & $89(63.6)$ & $113(77.4)$ \\
\hline
\end{tabular}

* Altogether 14 women within unknown ages were excluded.

† Percentages are based on respondents to each question.

$\ddagger$ Including perimenopausal women. and $16.7 \%$ said there were contraindications (of which breast cancer accounted for nearly half). Only $2.6 \%$ said their GP was reluctant. "Other reasons" were cited by $21.5 \%$, including general reluctance to take medication and a feeling that it was unnatural. Several women also mentioned inconclusive evidence of benefit.

\section{ASSOCIATIONS WITH HRT USE}

To investigate associations with HRT use in perimenopausal and postmenopausal women, a subgroup of 875 subjects was defined. This group excluded women who were menstruating regularly and those who had started HRT premenopausally who were less than 51 years old at the time of the survey (the mean age of natural menopause in this study).

Age adjusted odds ratios for the association of some key variables with ever use of HRT are shown in table 3. HRT use was strongly associated with age, and independently with type of menopause, the presence and severity of menopausal symptoms, ever use of hormonal contraception, and a family history of osteoporosis. HRT users were also more likely to have used non-hormonal preparations for the menopause or its sequelae. Lifestyle factors showing a significant association with HRT use were vigorous physical activity once or more per week, the use of reduced rather than full fat milk, and an attempt to increase the intake of certain types of food (mainly fruit, vegetables, and fibre). GPs were more likely to have used HRT than doctors working in a hospital or the community health service.

A family history of breast cancer or vascular disease was not associated with HRT use; however, ever users with a family history of breast cancer were significantly less likely to be current than past HRT users. The 50 women with a personal history of breast cancer were less likely to have started HRT and the 16 ever users were less likely to have continued it than women without such a history.

ASSOCIATIONS WITH DURATION OF USE

Associations were sought with length of HRT use by defining a group of women who were eligible to have taken HRT for at least seven years. This group consisted of all the ever users who were at least seven years postmenopausal or who had started HRT premenopausally at least seven years before the survey. Key variables were compared in relation to short duration (less than two years versus two years or more) and long duration (less than five years versus five years or more) use and age adjusted odds ratios for the latter comparisons are shown in table 4. Long term use was significantly more common both in women who had taken HRT for symptom relief and in those who cited prevention of osteoporosis. Ever use of hormonal contraception was strongly related to long term use. Life style factors showed no particular association with duration of use, apart from a slight excess of women attempting dietary modification among long term users. Short term use was significantly more common in those who had experienced side effects. 
Table 3 Associations with ever use of HRT (perimenopausal and postmenopausal group) ( $n=875$ )

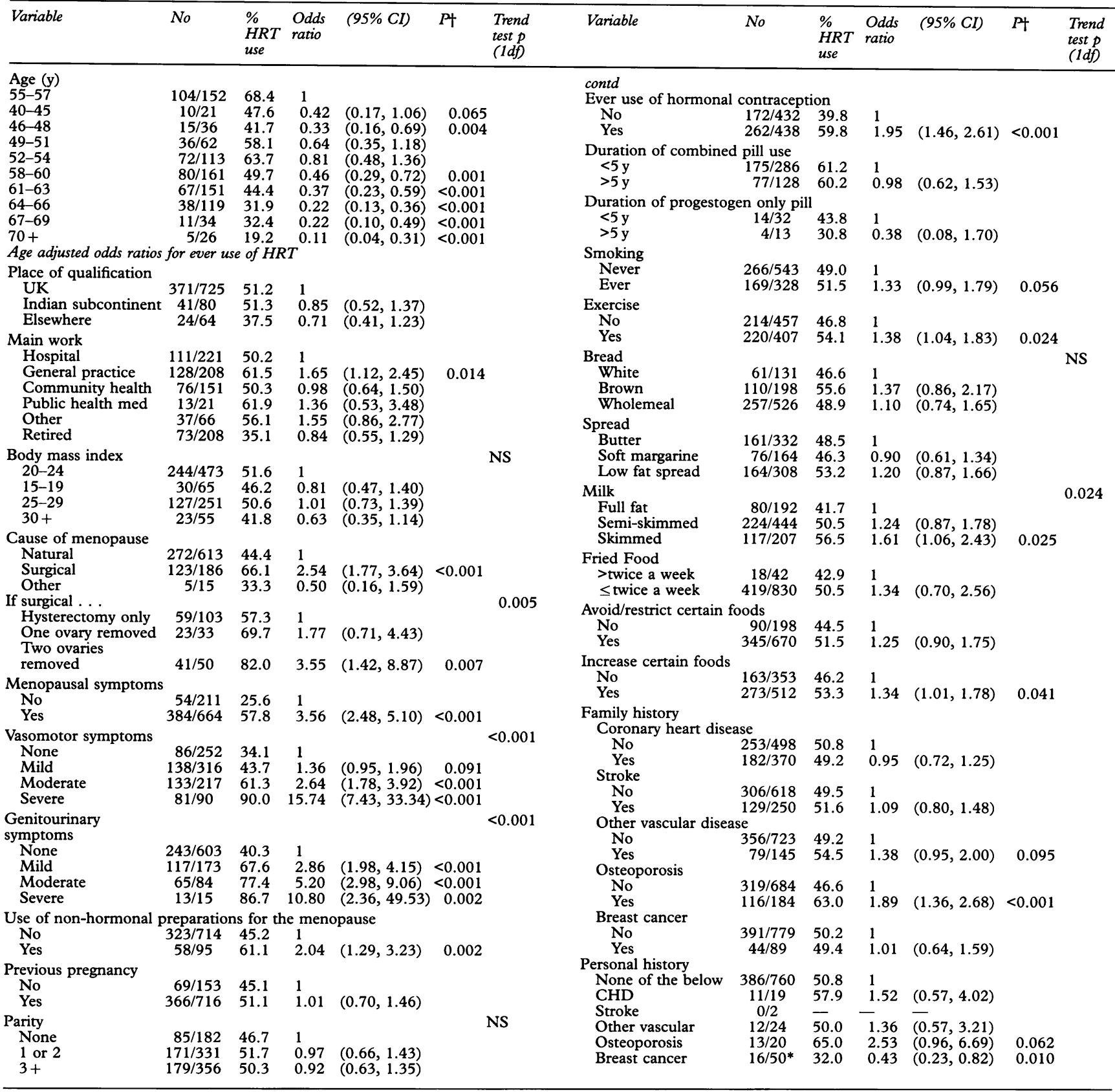

$\dagger \mathrm{p}$ values $>0.1$ are omitted.

* Includes 5 women with osteoporosis or CHD as well—none of whom used HRT. NS $=$ not significant $(p>0.05)$

\section{Discussion}

While most women doctors take HRT for symptom relief, a substantial number also do so to prevent cardiovascular disease and more particularly osteoporosis. In our survey, a significant proportion were taking HRT only for long term prevention. The high prevalence and duration of HRT use by women doctors compared with other women may thus reflect not only that many started on their own initiative, but also greater awareness of the potential benefits of HRT in disease prevention. Women doctors may be pacesetters in this respect, as for another aspect of health related behaviour, cigarette smoking, where change preceded that in the general population ${ }^{11}(6.7 \%$ of the respondents in this survey were current smokers).

The precise extent to which the trends shown for women doctors can be extrapolated to the
Associations of key variables with $\geq 5$ years vs $<5$ years use of $H R T$

\begin{tabular}{llllll}
\hline Variable & $N o>5 y$ & \% long term & Odds ratio & $(95 \%$ CI $)$ & $p$ \\
\hline $\begin{array}{l}\text { Menopausal symptoms } \\
\quad \text { No }\end{array}$ & $8 / 26$ & 30.8 & 1 & & \\
$\quad \begin{array}{l}\text { Yes } \\
\text { Reasons for using HRT }\end{array}$ & $90 / 170$ & 52.9 & 2.9 & $(1.13,7.56)$ & 0.0274 \\
$\quad \begin{array}{l}\text { Symptom relief } \\
\quad \text { No }\end{array}$ & $18 / 54$ & 33.3 & 1 & & \\
$\quad \begin{array}{l}\text { Yes } \\
\quad \text { Prevention of osteoporosis }\end{array}$ & $77 / 136$ & 56.6 & 2.56 & $(1.31,5.04)$ & 0.0062 \\
$\quad 30 / 79$ & 38.0 & 1 & & \\
$\quad$ Yes & $65 / 111$ & 58.6 & 2.60 & $(1.39,4.89)$ & 0.0029 \\
$\begin{array}{l}\text { HRT side effects } \\
\quad \text { No }\end{array}$ & $64 / 110$ & 58.2 & 1 & & \\
$\quad$ Yes & $32 / 82$ & 41.5 & 0.54 & $(0.30,0.97)$ & 0.0387 \\
Ever use of hormonal contraception & $31 / 89$ & 34.8 & 1 & & \\
$\quad$ No & $65 / 105$ & 61.9 & 3.33 & $(2.72,3.96)$ & $<0.001$ \\
$\quad$ Yes & & & & & \\
\hline
\end{tabular}


wider female population remains uncertain. Use of HRT is likely to increase as a wider range of preparations and regimens are developed and more information becomes available on its preventive effects. Women doctors' own high usage may reinforce this, given the importance of general practitioners' views on women's choices in this area. ${ }^{11}$ The positive association with prior oral contraceptive use shown in this and other ${ }^{72-15}$ studies also supports the trend to greater use, as successive cohorts of women with increasing oral contraceptive exposure ${ }^{16}$ reach the menopause.

However, women's judgments on whether to use HRT and for how long are finely balanced and may be critically influenced by current assessments of the evidence of benefit and risk. The precise health impact of long term HRT is difficult to quantify because of the difficulty in eliminating the effects of bias and confounding from the associations seen in observational studies. In particular, it has been suggested that women who take HRT may be a self selected, healthier group than those who do not, on the basis of sociodemographic and behavioural characteristics, ${ }^{67}$ and thus at intrinsically lower risk, particularly of coronary heart disease. Despite attempts to control for a variety of behavioural factors in epidemiological studies, ${ }^{12}{ }^{13}$ one review ${ }^{17}$ concluded that a risk reduction of $20 \%$ was a more plausible estimate than the more usually accepted $50 \%{ }^{3}$

In the present survey, correlations were sought between HRT use and a number of lifestyle factors. The results showed positive associations with increased physical activity and dietary modification in the direction of low fat milk consumption and increased intake of fruit, vegetables, and fibre. While these self reported behaviour patterns have not been validated, they nevertheless reflect a perceived attempt to adopt a lifestyle that is healthier. Investigating this further we fitted a term in the linear model which grouped women who reported all three of these factors. The odds ratios for ever use of HRT was $2.1(95 \% \mathrm{CL} 1.15,3.68)$ relative to those who claimed none of these factors. When we attempted to eliminate the effect of these lifestyle factors on the odds of HRT use, by including all variables in the model as potential confounders, the most resilient was physical activity. The remaining two had little residual effect if the other variables were indeed true confounders. Thus, even within a relatively homogeneous population, there is some evidence for subtle variations in behaviour which may be difficult to allow for in non-randomised studies. These data support the hypothesis that those women taking HRT may be less disease prone for reasons unconnected with HRT use itself.

Factors deterring the women in this survey from long term HRT use included continued bleeding and breast cancer risk. While the former may be alleviated by the amenorrhoeic regimens now becoming available, breast cancer remains a cause for concern. Studies carried out before our survey, involving mainly oestrogen use alone, were consistent with a small increase in risk following prolonged treat- ment. ${ }^{18}$ More recent data from the nurses' health study are less reassuring, suggesting an appreciable increase in risk at five years in current users of both oestrogen only and combined regimens. ${ }^{19}$ While these data are at variance with other recent studies, the relationship between HRT and breast cancer, particularly in women who may be at intrinsically increased risk, will continue to need clarification. ${ }^{420}$

Women are less concerned about potential reduction of coronary heart disease than of increased susceptibility to breast cancer. $^{21}$ While knowledge of the role of HRT in prevention of osteoporosis is increasing, ${ }^{22}$ the uncertainty as to the precise benefits of coronary heart disease reduction will make this less persuasive to many women than potential breast cancer risk and a substantial minority may never take up HRT, at least until the benefitrisk ratio is more clearly established.

Funding: by the Department of Health.

1 Isaacs AJ, Britton AR, McPherson K. Utilisation of hormone replacement therapy by women doctors. $B M \mathcal{F} 1995 ; 311$ : 1399-401.

2 Ettinger B, Genant HK, Cann CE. Long-term estrogen replacement therapy prevents bone loss and fractures. $A n n$ Intern Med 1985;102:319-24.

3 Stampfer MJ, Colditz GA. Estrogen replacement therapy and coronary heart disease: a quantitative assessment of the epidemiologic evidence. Prev Med 1991;20:7-63.

$4 \mathrm{McPherson} \mathrm{K}$. Breast cancer and hormonal supplements in postmenopausal women. $B M \mathcal{F}$ 1995;311:699-700

5 Henderson BE, Paganini-Hill A, Ross RK. Decreased mortality in users of estrogen replacement therapy. Arch Intern Med 1991;151:75-78.

6 Barrett-Connor E. Postmenopausal estrogen and prevention bias. Ann Intern Med 1991;115:455-56. 7 Egeland GM, Kuller LH, Matthews KA, Kelsey SF, Cauley J, Guzick D. Premenopausal determinants
estrogen use. Prev Med 1991;20:343-49.

8 Dean AG, Dean JA, Burton AH, Dicker RC. Epi Info, Version 5: a word processing, database and statistics program for epidemiology on micro-computers. Stone Mountain, Georgia. USD Inc, 1990.

9 SPSS for Windows, Release 6.0. Chicago, Illinois. SPSS Inc, 1993.

10 Doll R, Peto R. Mortality in relation to smoking: 22 years observations on female British doctors. $B M F$ 1980;1:96771 .

11 Ferguson KJ, Hoegh C, Johnson S. Estrogen replacement therapy: a survey of women's knowledge and attitudes. Arch Intern Med 1989;49:132-36.

12 Pettiti DB, Perlman JA, Sidney S. Noncontraceptive estrogens and mortality: long-term follow-up of women in trogens and mortality: long-term follow-up of women in

13 Stampfer MJ, Colditz GA, Willett WC, Manson JE, Rosner B, Speizer FE, Hennekens CH. Postmenopausal estrogen therapy and cardiovascular disease: ten-year follow-up from the Nurses' Health Study. $N$ Engl F Med 1991;325: 756-62.

14 Griffiths F, Jones K. The use of hormone replacement therapy; results of a community survey. Family Practice 1995;12:163-65.

15 Lancaster T, Surman G, Lawrence $M$, et al. Hormone replace therapy: characteristics of users and non-users in a British general practice cohort identified through cohort identified through Health 1995;49:389-94.

16 Villard-Mackintosh L, Vessey MP, Jones L. The effects of oral contraceptives and parity on ovarian cancer trends in women under 55 years of age. Br $\mathcal{F}$ Obstet Gynaecol 1989; 96:783-88.

17 Meade TW, Berra A. Hormone replacement therapy and cardiovascular disease. Br Med Bull 1992;48:276-308.

18 Steinberg KK, Thacker GB, Smith SJ, et al. A meta-analysi of the effect of estrogen replacement therapy on the risk of breast cancer. $\mathscr{F A M A}$ 1991;265:1985-90

19 Colditz GA, Hankinson SE, Hunter DJ, et al. The use of estrogens and progestins and the risk of breast cancer in postmenopausal women. New Engl f Med 1995;332: 1589-93.

20 Howell A, Baildam A, Bundred N, Evans G, Anderson E. 'Should I take HRT, doctor?' Hormone replacement therapy in women at increased risk of breast cancer and in survivors of the disease. Fournal of the British Menopause Society 1995;1:9-17.

21 Pilote L, Hlatky MA. Attitudes of women toward hormone therapy and prevention of heart disease. Am Heart $\mathcal{f} 1995$; 129:1237-38.

22 Sinclair HK, Bond CM, Taylor RJ. Hormone replacement therapy: a study of women's knowledge and attitudes. $B r$ 7 Gen Pract 1993;43:365-70. 